\title{
Tiempos de Guerra. El soldado que salvó Spielberg
}

\section{Ramón E. CAMAÑO-PUIG, Laura ALMUDÉVER-CAMPO}

Departamento de Enfermería. Universidad de Valencia (España).

Autor para correspondencia: Laura Almudéver-Campo. Correo electrónico: Laura.Almudever@uv.es; laura.alca3@gmail.com

Recibido el 5 de abril de 2019; aceptado el 23 de junio de 2019.

Cómo citar este artículo: Camaño Puig RE, Almudéver Campo L. Tiempos de Guerra. El soldado que salvó Spielberg. Rev Med Cine [Internet] 2019;15(4): 231-6. DOI: http://dx.doi.org/10.14201/rmc2019154231236

\section{Resumen}

Durante la Segunda Guerra Mundial, concretamente tras el Desembarco de Normandía, unos soldados norteamericanos capitaneados por Jonh Miller deben arriesgar sus vidas para salvar al soldado James Ryan, cuyos tres hermanos han muerto en la guerra. Lo único que se sabe del soldado Ryan es que se lanzó con su escuadrón de paracaidistas detrás de las líneas enemigas. El jefe del estado mayor ha ordenado devolverlo a su hogar, en lowa, donde lo espera su desconsolada madre. Se trata de un filme bélico donde la muerte está siempre presente y en la cual, el soldado Ryan rememorará todas las vicisitudes por las que tuvieron que pasar los soldados para salvarlo.

Palabras clave: guerra; muerte; vida; lucha; soldado.

\section{Times of War. The Soldier who saved Spielberg}

\section{Summary}

During the Second World War, specifically after the Normandy Landing, American soldiers led by John Miller must risk their lives to save Private James Ryan, whose three brothers have died in the war. The only thing that is known about Private Ryan is that he launched himself with his squadron of paratroopers behind the enemy lines. The chief of staff has ordered him returned to his home in lowa, where his bereaved mother awaits him. It is a war film where death is always present and in which Private Ryan will remember all the vicissitudes that the soldiers had to go through to save him.

Keywords: warfare; death; life; fight; soldier. 
Desde el inicio de Salvar al soldado Ryan / Saving Private Ryan (1998) de Steven Spielberg podemos dilucidar cuál va a ser el carácter unitario que regirá la historia que su director nos quiere contar. Ese gran primer plano de la bandera de los Estados Unidos (EEUU) es lo que hará converger a todas las directrices del film. Directrices que formarán un ciclo, comenzando y acabando el relato fílmico con dicho plano. Ya no sólo por el propio simbolismo patriótico que puede reflejar una bandera, sino también por las propias connotaciones que de ella surgen: derechos humanos, constitucionalidad de una nación, civismo, y algo que tiene muy claro Spielberg, la moralidad de la que debe embeberse una sociedad.

Pero su director no sólo nos muestra la bandera de su nación como icono referencial. A través de una depurada técnica fotográfica, el colorido impreso en esa bandera de celuloide definirá el resto de la película. Se nos muestra la realidad de la forma más clara y palpable posible, para ello se apoya en una fotografía en color donde los tonos se encuentran apagados, mortecinos, jugando un papel dramático importantísimo para narrar la historia desde un punto de vista concreto.

Haciendo uso del flashback, introducido por un hombre avanzado en años, se nos adentra en el 6 de junio de 1944, momento en que se va a producir el Desembarco de Normandía. Desde este momento, Spielberg jugará con el espectador. Utilizando un travelling de acercamiento hacia el detalle de los ojos del anciano, se nos mostrará la mano temblorosa de un soldado, y al tiempo que se utiliza un estudiado lenguaje cinematográfico, el plano se abrirá de nuevo, mostrándonos su rostro, sus ojos, su mirada perdida en el miedo que precede a la batalla, comprobando que el soldado se encuentra en una barcaza rumbo hacia la playa de Omaha.

Al mismo tiempo que se ha producido el flashback podemos entender que los dos hombres son el mismo. Sin embargo, tendremos que ir avanzando en la historia del film para poder averiguar que la persona que recuerda no es el capitán Miller (Tom Hanks). Historia que es recordada para el espectador, el cual podrá funcionar como sujeto pasivo o sujeto activo de la misma según le permita su bagaje cultural, o incluso, su propia experiencia de tan fatídica contienda.

Es con toda la secuencia del Desembarco donde la capacidad de realización y de narración visual de Spielberg queda en su punto más álgido. Rodada toda ella con cámara al hombro, se consigue así la sensación buscada: introducirnos totalmente en el horror, desconcierto e impotencia que se puede sentir al formar parte de una batalla. Se plasma esa realidad ofreciendo a todo ello un carácter de documental de guerra rodado en vivo y en 16 $\mathrm{mm}$. La cámara participa en la acción, parece ser uno más en la batalla, la cual no sabe dónde y de qué forma estallarán las bombas o harán impacto las balas. Balas disparadas sin rumbo fijo, sino lanzadas por doquier para conseguir una mayor consecuencia: muerte y destrucción, el enemigo debe ser aniquilado.

La subjetividad en toda la secuencia es total. No solo porque muchos de los planos sean subjetivos del propio capitán Miller, o de cualquier otro soldado de su compañía, (a destacar como la cámara se tira por la borda de la barcaza y se sumerge en el agua donde la confusión es mayor), sino también porque al mismo tiempo que el director nos muestra todas estas escenas, se está consiguiendo que el espectador se sienta angustiado por el horror que está viviendo, que no es más que una imagen de la realidad. Realidad creada desde el punto de vista de su narrador, basándose en la historia real documentada. En la historia de los hombres partícipes en la contienda, de aquellos hombres que sintieron y sobrevivieron al Día D. Así, somos testigos, como espectadores de la representación cinematográfica, del desconcierto, del horror, de la confusión, y del ritmo frenético y desgarrador que se respira en la secuencia inicial y desencadenante del relato.

Destacable el momento en el que vemos a un soldado buscando entre sus compañeros muertos, el brazo del que ha sido mutilado. Al encontrarlo lo coge y echa andar sin rumbo fijo, conmocionado, perdido en la barbarie. Se respira un sin sentido generalizado, los actos no tienen justificación. Los cuerpos de los hombres yacen destrozados en la playa. O la no menos desagradable escena en la que un soldado aparece reventado llamando a su madre desesperadamente, aunque eso sí, mostrada con una impactante crudeza, sobre todo porque ya nadie puede hacer nada por él, sus compañeros, el resto de los hombres, contemplan la muerte con el horror y la conmoción propia de estar visionando una locura.

De esta manera, es magistral el momento en el que el capitán Miller consigue, por fin, llegar a la playa, para contemplar la destrucción absoluta de sus hombres. En donde las bombas y las balas llegan a ensordecer la mortal escena. Su conmoción no le permite ni escuchar los atroces alaridos de dolor y desesperación. Y es aquí donde Spielberg llega a conectar en mayor medida con el espectador.

Con todo ello, la recreación del desembarco nos satura a imágenes frenéticas, cargadas de gran emotividad 
y dramatismo, consiguiendo que esa gran intensidad llegue a tocar la fibra sensible del espectador.

Pero para ello necesita una causa, algo que mueva los engranajes de la narración futura. Si la consecuencia directa de la muerte de los hombres en la guerra es la comunicación a sus familiares de esas pérdidas, causa y efecto de la humanidad y sus consecuencias, más ardua será la labor de comunicar a una madre, a la representación de las madres, la pérdida de sus hijos. Así, de manera estudiada y calculada, la cámara nos conducirá hacia un soldado muerto, cuya mochila lleva grabado su nombre, Ryan (Matt Damon), sobre la fría y húmeda arena de la playa, allí, junto a numerosos hombres que yacen derramando su sangre acompañando a los peces sin vida, como iguales en la certeza de la muerte.

Y Spielberg llega a entramar toda una narración hilvanada a conciencia desde el principio. Para conseguirlo se apoya en un nutrido guión que guarda ciertas sorpresas en su desarrollo. Construyendo una personalidad para cada uno de sus personajes intenta que esa fibra sensible, que busca desde el principio, se mantenga hasta el final.

El capitán Miller es un hombre inteligente, serio, que funciona como un padre para toda su compañía. El maestro de redacción que sólo desea que la guerra no le haya cambiado demasiado. Su propia inteligencia le lleva a sentir miedo, pánico, pero que no puede ni debe transmitir a sus soldados por su propia condición de superior. Incluso llega a ser palpable el que Miller se cuestione las órdenes de buscar a un único hombre, pudiendo poner en peligro la vida de muchos otros, pero su rango y experiencia le obligan a callar. Sufrimiento que guardará para sí mismo, intentando conducir de la mejor forma posible a sus hombres hacia el objetivo. Su personaje contrasta totalmente con la figura del cabo Upham (Jeremy Davies), el otro intelectual, ese soldado que está aterrado durante toda la historia y que incluso llega a hacerse antipático para el espectador.

Otro personaje construido con dramatismo latente es el de Mellish (Adam Goldberg), el judío. Aquel que encontrará un cuchillo de las juventudes hitlerianas y dirá, "ahora cortará el pan del Sabbath". Sin embargo, quedarse con ese cuchillo será su perdición, ya que éste será el instrumento que segará su vida. Muerte que encontrará en manos de un alemán. Muerte buscada como un ciclo predeterminado, un destino escrito con el que no podemos estar de acuerdo.

Wade (Giovanni Ribisi), el sanitario, funciona como un pilar en el que todos saben que pueden confiar.
Pero dramático será el momento en el que es alcanzado por las balas alemanas. El personaje ha llegado a penetrar en la mente del espectador. Hemos llegado a conocerlo. Pensamos que su presencia es necesaria en el grupo. Pero quien "mueve los hilos" ha decidido eliminarlo. Escena sobrecogedora con una gran carga de profundo dramatismo, la impotencia generalizada que sufren sus compañeros, aquellos que ven como se le escapa la vida por una decisión del capitán Miller.

Impotencia ante la muerte, incluso del que sabe, y por saberlo más impotente todavía. Ejemplo de desesperación, pero a la vez de calma y tranquilidad. El sanitario herido en el abdomen, pide que le señalen el lugar del orificio. Reconoce la gravedad de la herida, y aunque los demás tratan de consolarle y quitarle importancia, él admite lo inevitable y pide más morfina. Sabiéndose herido de muerte, conoce que la morfina le puede ayudar, e incluso, facilitarle la muerte.

Esta escena desemboca en la irracionalidad, en venganza, quieren matar a un prisionero capturado, la muerte no se comprende, cualquier intento de comprensión conduce a la irracionalidad. El capitán Miller llora desconsoladamente, se inhibe del desenlace que se avecina, la muerte del alemán capturado, quien no siendo consciente bromea, cree que ha conjurado el riesgo, tal y como al final se produce. Esto crea desasosiego entre los hombres de la patrulla. El capitán argumenta de forma racional y ética, luchando contra sus instintos atávicos, de guerrero, de exterminador, apelando a la idea de que "cada vez que mato me siento más lejos de casa". Miller no quiere dar el paso, no quiere romper sus anclajes, no quiere dar rienda suelta a sus instintos, quiere volver a casa sin abandonar la humanidad y la cultura, sin que le turbe su mala conciencia al pensar en los enemigos muertos.

Así como el personaje del sargento Horvath (Tom Sizemore), perro fiel de su capitán, hombre de más edad que no pondrá nunca en duda una decisión de su superior. Hombre duro pero de raíces arraigadas, que colecciona en pequeños envases de metal tierra de los lugares en los que ha tenido que batallar. Tierra de aquellos lugares que han sido testigos de la guerra y de la muerte. Tierra que conlleva vida en sí misma y que representa vida para el hombre que la recoge, el humus de humanidad y vida, que representa un triunfo de aquel que la posee, pero que en definitiva no lleva más que a recordar la muerte que estuvo impregnada en ella.

Y si algo resultará trascendental en la narración del relato fílmico, será la decisión crucial que adoptará el 
grupo de soldados. Convencidos al final por el cabo, por el cobarde inteligente, para que no maten al soldado alemán en el campo de la estación de radar. Su puesta en libertad llevará consecuencias desastrosas. La historia narrada volverá a guardarse un as en la manga. El soldado alemán no será otro que el que dará muerte al capitán Miller. Sin embargo, en una escena que anuncia el fin del relato, en donde el cabo cobarde es testigo de privilegio de la muerte de su capitán, decidirá hacer lo único que considera correcto: disparar sólo una bala de la que es capaz en toda la contienda, y dar muerte al soldado alemán.

Así, la muerte del grupo encierra un ciclo iniciado desde la lluvia de sentimientos. Lluvia que se hace presente en el camino a seguir por el grupo. Lugar en donde los soldados quieren salvar a una desdichada niña. Lluvia que limpiará la sangre de una carta, sangre del primer soldado caído, cuya carta se convertirá en testigo mortal del grupo. Carta que circulará entre los compañeros, de mano en mano, sólo para poder hacer realidad el fin implícito en esa carta: la comunicación a los progenitores, al padre y a la madre, de que siguen en la brecha. La muerte no vencerá y existe una esperanza.

"Hágase usted digno de esto, merézcalo..." Son las últimas palabras del capitán Miller a Ryan. El soldado Ryan vuelve a Francia acompañado de su familia, y va de visita al cementerio en el que se encuentra enterrado el capitán Miller. Una vez ante la tumba, llora conmovido por la visión y el recuerdo de aquellos que fueron sus compañeros. En un escenario, donde la muerte está presente, el soldado Ryan refleja sus pensamientos dirigiéndose al capitán Miller: "Mi familia ha venido hoy conmigo, ha querido acompañarme. A decir verdad, no sabía lo que sentiría al volver aquí. Todos los días recuerdo lo que usted me dijo en aquel puente. He intentado vivir mi vida lo mejor posible, iojalá! haya sido suficiente y al menos ante sus ojos haya sido digno y merecedor de cuanto se ha hecho por mi". En el plano final se aprecia la conjunción de un presente conectando un pasado, los muertos enterrados en el cementerio, y un futuro, la esperanza de los jóvenes de la familia.

La película adopta desde el primer momento una perspectiva autobiográfica, en la cual el soldado Ryan rememorará todas las vicisitudes por las que pasaron un grupo de soldados durante la II Guerra Mundial. Soldados que amontonados en las barcazas de desembarco están ensimismados en sus pensamientos, para momentos después, verse envueltos en una auténtica carnicería de la que cabe escapar, pero escapando al saltar por la borda son arrastrados al fondo por el peso del equipo o alcanzados por las balas. Las escenas muestran cómo los hombres mueren realmente, o debiera decirse más apropiadamente cómo murieron. La guerra se muestra en todo su esplendor, con un verismo impresionante, en donde los hombres no mueren uno a uno, sino multitudes de ellos. A menudo morían decenas de miles en un solo día. En donde, quizás un proyectil pueda ser esquivado afortunadamente, para no habiendo tenido tiempo de pestañear, un segundo proyectil te siegue la vida. La guerra, mostrada así, nos hace abandonar la idea de contingencia de la muerte y convierte la vida al fin y al cabo en muerte, recuperando el sentido original de la vida ${ }^{1}$.

El acceso a la playa se realiza bajo una espesa lluvia de balas, la percepción se altera, la secuencia se ralentiza, el agua, fuente de vida, está roja, y en ella los peces se mecen muertos. Paralelamente al desarrollo de estas acciones, al otro lado del Atlántico, una empleada gubernamental se percata de la muerte, en distintas batallas, de tres hermanos, los hermanos de Ryan. El último de los hijos de una familia, y éste todavía se encuentra en el frente. Los mecanismos de preservación se ponen en marcha, había que evitar más sufrimiento a una familia, a esa familia. Sufrimiento mostrado bajo la perspectiva del calor del hogar, cuando un coche oficial se dirige hacia la finca de los Ryan llevando consigo un fatídico mensaje. En donde el silencio de las palabras no pronunciadas cobra un sentido sobrecogedor desde la mirada del hogar. Mirada dispuesta desde las fotografías de aquellos que no volverán al lugar que les vio nacer, en donde la madre quedará con sus recuerdos y su sufrimiento, abatida al imaginar la pérdida de sus hijos. Se debía combatir la esterilidad de la existencia, había que encontrar a Ryan, a fin de evitar el vacío en la vida de los padres, y de esta manera combatir la muerte, combatir la anomia.

La búsqueda se organiza, los soldados a los que se les encomienda la misión tienen que buscarle en un medio totalmente hostil, y en el que la muerte, de una manera u otra, está siempre presente. Se suceden las preguntas sin respuesta. ¿Qué sentido tiene arriesgar la vida de ocho hombres por uno solo? ¿La vida de uno vale por más? Todo ello con ánimo de racionalizar la misión. ¿Pero puede racionalizarse la guerra? ¿Y la muerte?

Y en el intento de dar respuestas a los actos del hombre se encuentra la figura de Jackson (Barry Pepper), el francotirador, aquel que se encomienda siempre a Dios para llevar a cabo sus muertes, para llevar a cabo su propia cruzada. En sus propias palabras afirma, "Dios me concedió un don especial al convertirme en un instrumento de guerra". Dotado de una extraordinaria puntería, es capaz de dormir plácidamente al acabar la jornada, llamando la atención de sus propios compañeros, los cuales, cobijados 
bajo el techo de una capilla en ruinas comentan, "Si Dios está con nosotros quien está con ellos". El cabo Upham, ese cobarde inteligente, rectificará diciendo: "Si Dios está con nosotros quien estará contra nosotros". Frase hecha realidad cuando la mortífera munición de un carro blindado segará la vida de Jackson, momento en que su puntería deja de ser efectiva. Momento en el que se hace visible para el enemigo, la perdición de cualquier francotirador, siendo él mismo, y no la Providencia, quien marca su destino.

El recuerdo de lo sucedido para Ryan supone una relectura de la experiencia, elaborada y comprendida a través de una toma de conciencia trascendental de lo que ocurrió en su propia vida. La película, incluso en términos de ficción, funciona como un texto de referencia, con aspiraciones de texto histórico, tratando de aportar información respecto de una realidad exterior al texto, la cual puede ser sometida a verificación, a contrastación histórica.

La historia relatada vendrá condicionada a partir de los distintos modos de lectura que origina. Prueba de ello son en sí mismas estas líneas, a partir de las cuales hemos llegado a establecer diferentes premisas que configuran el contenido de este texto. Premisas, las cuales están incorporadas al conjunto de la película desde una perspectiva paratextual, nadie habla de muerte en una película de guerra, pero la muerte lo inunda todo, la aprehende, se hace un todo con ella, con la película.

Se establece una relación especular entre el que relata y el relatado, entre el individuo actual y el pasado, entre aquello que desapareció, que está muerto, y cuya única llama de vida permanece en la memoria del que relata y de los vivos. Implicando todo ello, lo vivo y lo muerto, el pasado y el presente en un proceso de lectura, de visionado, en el cual se determinan mutuamente. Los individuos que se describen, pretenden compartir la identidad de lo que en realidad fueron y, a los cuáles, se hace referencia a través de la temática del texto audiovisual que desposee y restituye, que desfigura y restaura.

Posiblemente una de las escenas más impactantes sea aquella en la que tres de los miembros del grupo comienzan a buscar, entre las chapas de identificación de soldados muertos, la de Ryan. La acción de búsqueda se convierte en un juego, frente a la columna de soldados que desfila por la carretera, viendo la escena. Se construye una metáfora, en la que ésta reorganiza el significado, la visión de las cosas. Los soldados que pasan ven muerte. A la muerte, simbolizada en las chapas iden- tificativas, muerte banalizada. Sólo una percepción distinta, profesional y educada en esa línea, la del sanitario que interviene llamando la atención acerca del significado de lo que está ocurriendo, aporta racionalidad y finaliza el espectáculo.

La historia de la humanidad es un sucedido de luchas y guerras, de muerte y destrucción. En la II Guerra Mundial se calcula que murieron alrededor de cincuenta millones de personas, a las que hay que sumar otros cuarenta millones de huérfanos o refugiados. Muerte y destrucción generada por instinto, y que resurge constantemente a través de un sutil tejido cultural que apenas puede controlar tanta barbarie. Hoy, hay más de 80 guerras activas en el mundo. Unas veces por no aparecer en los medios de comunicación, y otras por ser bombardeados implacablemente con sus imágenes hasta dejar de verlas, nos dejan impasibles. Imágenes que llegan a nuestros ojos inesperadamente, velozmente, y nos muestran en un aquí y ahora, muerte ajena, la de otros, que consideramos accidental, y no nos va a tocar...

Ryan se comporta como un héroe, la irracionalidad, la camaradería, que provoca la guerra, imbrica a los individuos en una lógica guerrera en la que no cabe la discrepancia, la defensa de la propia opinión. En esta lógica, cuando encuentran a Ryan, éste se niega a marcharse, actúa sin opinión, en obediencia ciega a la lógica guerrera en la que está inserto, prevalece incluso por encima del pensamiento de la propia muerte, que acecha a cada momento, generando un giro surrealista.

La muerte llega poco a poco, se materializa de forma precisa en casi todos los miembros de la patrulla, y toma especialmente cuerpo en la agonía del capitán Miller, nuestro personaje más próximo, al que hemos acompañado, el que más conocemos. Aceptamos su muerte. Morimos identificados con él, le sobrevivimos y estamos de nuevo listos para identificarnos con otro héroe, al cual volveremos a sobrevivir. Esa es la magia que hace posible la ilusión cinematográfica.

\section{Ficha técnica}

Título: Salvar al Soldado Ryan. Título original: Saving Private Ryan.

País: Estados Unidos.

Año: 1998.

Director: Steven Spielberg.

Música: John Williams.

Fotografía: Janusz Kamiński.

Montaje: Michael Kahn. 
Guión: Robert Rodat.

Intérpretes: Tom Hanks, Tom Sizemore, Edward Burns, Matt Damon, Barry Pepper, Giovanni Ribisi, Adam Goldberg, Jeremy Davies, Vin Diesel, Ted Danson, Paul Giamatti, Max Martini, Dennis Farina, Harrison Young, Kathleen Byron, Harve Presnell, Dale Dye, Leland Orser, Bryan Cranston, Nathan Fillion, Ryan Hurst, Corey Johnson, Andrew Scott, Joerg Stadler, Dylan Bruno...

Color: color.

Duración: 169 minutos.

Género: bélico, drama.

Productoras: Mark Gordon Productions, DreamWorks, Paramount Pictures, Amblin Entertainment, Mutual Film Corporation.

Sinopsis: Segunda Guerra Mundial (1939-1945). Tras el desembarco de los Aliados en Normandía, a un grupo de soldados americanos se le encomienda una peligrosa misión: poner a salvo al soldado James Ryan. Los hombres de la

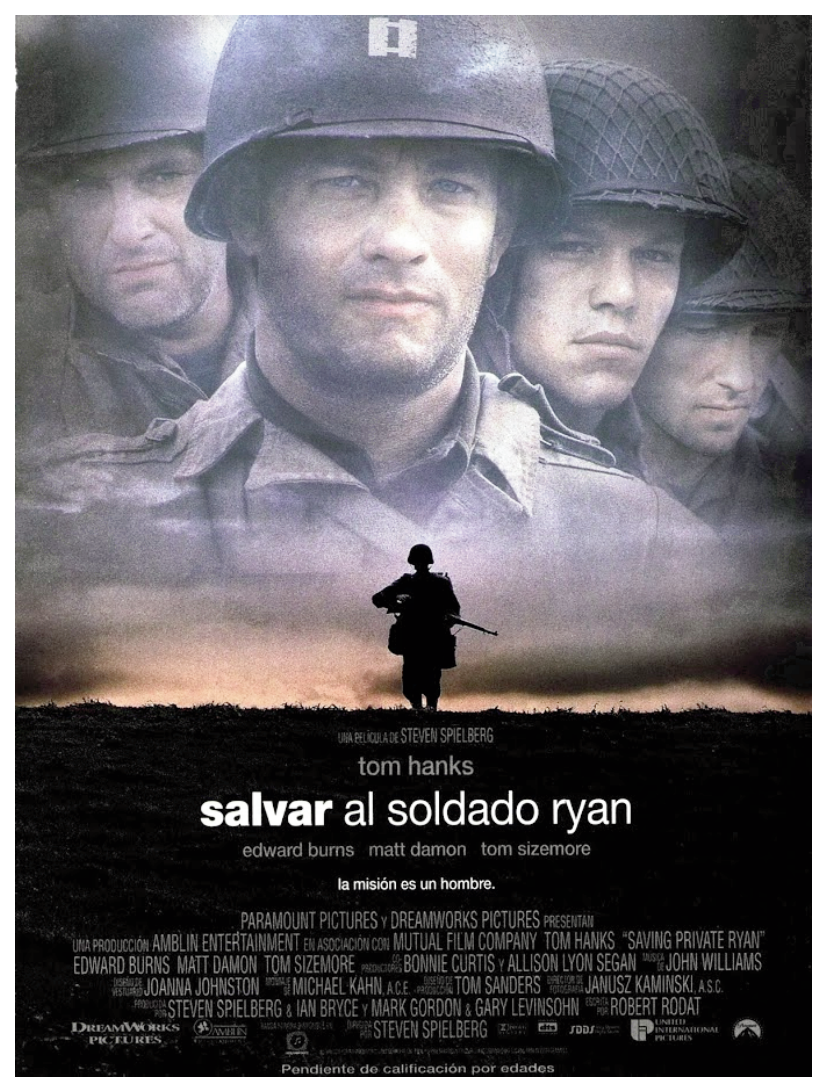

Cartel español. patrulla del capitán John Miller deben arriesgar sus vidas para encontrar a este soldado, cuyos tres hermanos han muerto en la guerra. Lo único que se sabe del soldado Ryan es que se lanzó con su escuadrón de paracaidistas detrás de las líneas enemigas.

Premios: Oscar al Mejor Director, Mejor Fotografía, Mejor Montaje, Mejor Sonido, Mejores Efectos Sonoros. Nominada a Mejor película, Mejor Actor Principal (Tom Hanks), Mejor guión original, Mejor Diseño de Producción, Mejor Maquillaje y Peluquería, Mejor Banda Sonora de Drama (1999).

\section{Enlaces:}

https://www.filmaffinity.com/es/film824508.html https://www.imdb.com/title/tt0120815

\section{$\underline{\text { Trailer }}$}

\section{Referencias}

1. Freud, S. ¿Por qué la guerra? Correspondencia entre Einstein y Freud. L'Interrogant 2017; (15). [Consultado el 2 de febrero de 2019].

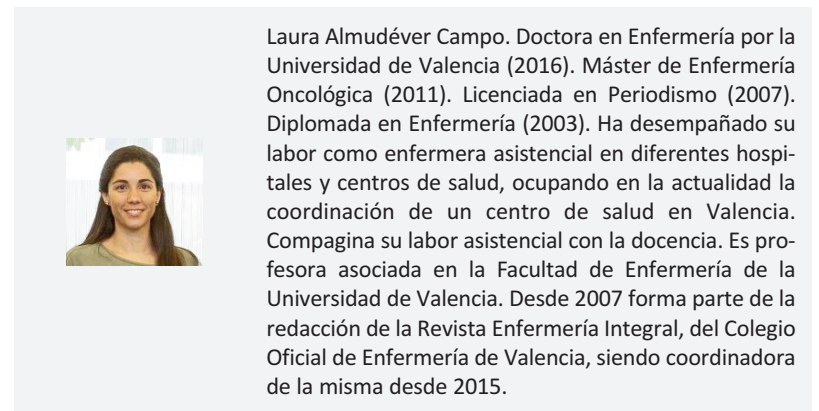

